\title{
Micrococcus luteus - Survival in Amber
}

\author{
C.L. Greenblatt , J. Baum , B.Y. Klein , S. Nachshon , V. Koltunov and R.J. Cano
}

\section{Abstract}

A growing body of evidence now supports the isolation of microorganisms from ancient materials. However, questions about the stringency of extraction methods and the genetic relatedness of isolated organisms to their closest living relatives continue to challenge the authenticity of these ancient life forms. Previous studies have successfully isolated a number of spore-forming bacteria from organic and inorganic deposits of considerable age whose survival is explained by their ability to enter suspended animation for extended periods of time. However, despite a number of putative reports, the isolation of nonspore-forming bacteria and an explanation for their survival have remained enigmatic. Here we describe the isolation of non-spore-forming cocci from a 120-millionyear-old block of amber, which by genetic, morphological, and biochemical analyses are identified as belonging to the bacterial species Micrococcus luteus. Although comparison of $16 \mathrm{~S}$ rRNA sequences from the ancient isolates with their modern counterparts is unable to confirm the precise age of these bacteria, we demonstrate, using complementary molecular and cell biological techniques, evidence supporting the view that these (and related modern members of the genus) have numerous adaptations for survival in extreme, nutrient-poor environments, traits that will assist in this bacteria's persistence and dispersal in the environment. The bacteria's ability to utilize succinic acid and process terpine-related compounds, both major components of natural amber, support its survival in this oligotrophic environment.

\section{Introduction}

There is an accumulating body of data reporting the persistence of bacteria in what are considered extreme and oligotrophic environments $[15,24,37]$. However, the mechanisms used by these bacteria to survive in such conditions are poorly understood. One extreme niche that has consistently yielded such bacteria is amber, from which single isolates and assemblages of multiple bacterial species have been characterized $[3,8,10,17]$. Amber is the fossilized remains of organic tree resins. As volatile terpenoids in these resins evaporate and dissipate under natural forest conditions they leave the nonvolatile fractions to become fossilized through progressive oxidation and polymerization. During the early stages of solidification microorganisms, and occasionally larger organisms such as insects [3], can become entrapped in the resins [31]. The preservation of these organisms allows for the possibility of isolating biological material of considerable age.

Early studies of microorganisms isolated from amber were limited in their ability to classify the bacterial species found and often lacked sufficient controls to ensure that no external contamination was accidentally being sampled [8, 31]. With improvements in extraction methods and bacterial genomics, the first report of verifiable bacteria from amber was Bacillus sphaericus, by Cano and Borucki [3], who isolated the microorganism from the abdomen of a fossil bee (entrapped in amber). This bacterium was shown to be genetically and biochemically different from extant members of the species [3]. Bacilli have dominated the species isolated from amber $[3,10,31]$. However, in one study, the isolation of a bacterial species was described which, because it differed significantly from known staphylococci relatives (for example, its fatty acid profile was unlike any related specific organism), was accepted as a new species Staphylococcus succinus [17]. Recent assemblages have yielded additional bacterial groups such as actinobacteria and cocci [10]. Whereas bacilli and actinobacteria are 


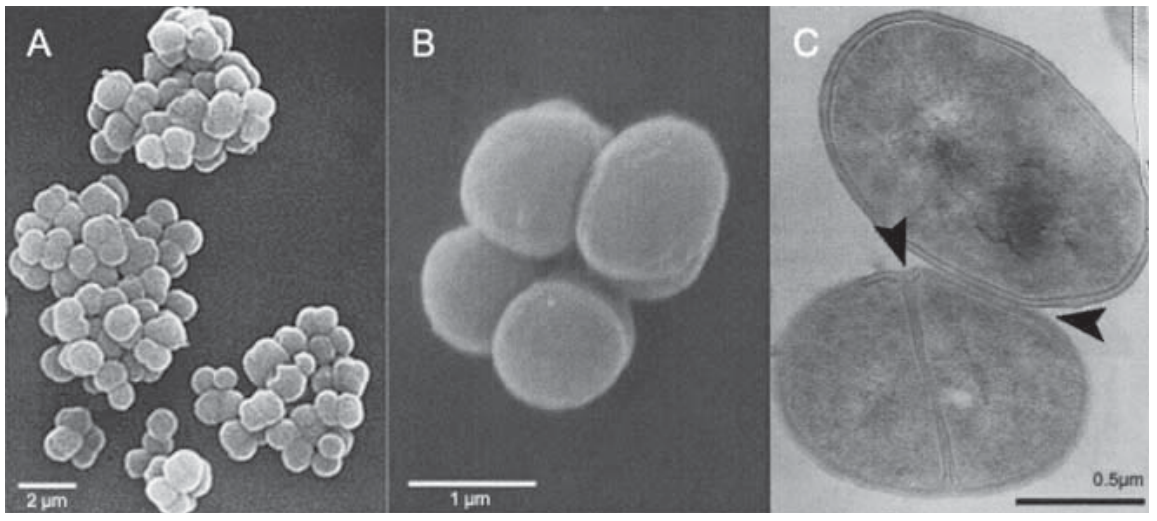

Figure 1. Electron micrographs (EM) of putative Micrococcus spp. isolated from amber (isolate 4). (A) Scanning EM showing bacterial clusters. (B) Scanning EM showing single tetrad. (C) Transmission EM of bacteria showing beginning of formation of tetrad by division in two planes (arrows). Scale bar shown in each panel. known for their longevity, being endowed with mechanisms for sporulation and hence the ability to survive long periods of time under complete dormancy [19, 27], cocci as a group are not especially known for their persistence, and their isolation from amber is somewhat surprising.

One group of cocci, the genus Micrococcus, has repeatedly been found under these and other extreme environments. Micrococci are Gram-positive bacteria, spherical in shape and often found in tetrad forms, the result of dividing in more than one plane (Fig. 1). They are nonmotile and do not form spores. The genus Micrococcus has several species, all described as strictly aerobic. Micrococcus luteus, the focus of research here, is characterized by the production of yellow water-insoluble pigments. Poinar and Poinar [31] described a number of bacteria, including Micrococci, isolated from amber in 1980 , but were unable to determine the precise species. More recently, an assemblage of bacterial isolates described by Greenblatt et al. [10], reported two different isolates which, despite a lack of correlation between their fatty acids and 16S rRNA sequences, were very likely to be species of Micrococcus. Furthermore, a database of some 1600 bacteria isolated from amber and copal, from the commercial firm Ambergene Corp, lists 33 isolated bacteria that have recorded characteristics for colony color, gram-stain type, and morphology, 28 of which had colonies that were yellow or shades thereof, and all were Gram positive. Moreover, eight showed the cocci in pairs or tetrads. It would therefore seem that the occurrence of Micrococcus spp. in amber is not a singular event.

Here we describe a study of bacteria isolated from 120-million-year-old amber deposits in Israel, subsequently identified as Micrococcus luteus. We present a hypothesis for the mechanisms that allow this bacterial species to survive in such extreme environments.

\section{Materials and Methods}

Isolation of Bacteria from Amber. To investigate the possibility of bacterial life within amber, a 1-g block of
Israeli amber (kindly provided by Professor Nissenbaum, excavated from the southern slopes of the Mount Hermon) was analyzed. It was taken from Lebanese amber lode dating to approximately 120 million years old (the discovery and collection is described in full by Poinar and Poinar [31], while the accuracy of the dating is described by Nissenbaum [29]). The methods followed for isolation were as detailed previously [10]. Briefly, to control for potential surface contaminants, the surface of the 1-g block was sterilized by immersion in $2 \%$ glutaraldehyde for $48 \mathrm{~h}, 10 \%$ bleach for $24 \mathrm{~h}$, and 70\% alcohol for $24 \mathrm{~h}$. The block was then placed in autoclaved trypticase soy broth (TSB) for 14 days. Following confirmation of sterility, the amber was aseptically submerged in liquid nitrogen for $15 \mathrm{~min}$, pulverized in a sterile mortar and pestle, and covered with sterile TSB $(\sim 5 \mathrm{~mL})$. Aliquots $(0.1 \mathrm{ml})$ of the amber flake-TSB suspension were plated onto TSB agar plates and incubated at $28^{\circ} \mathrm{C}$ and $37^{\circ} \mathrm{C}$ until growth was observed. Control TSB plates were included at every stage of the procedure to confirm sterility. Bacterial colonies from plates with the amber suspension were picked and regrown on separate plates.

Growth and Biochemical Characterization. A 1\% Bacto-tryptone medium (BD, Becton, Dickinson and Company, USA) was used for continual maintenance of the amber isolates. Incubation for all growth studies was at $37^{\circ} \mathrm{C}$. For investigation of colony formation, Czapek's salts [6] were used alone or supplemented with succinic acid (at concentrations up to $300 \mathrm{mM}$ ). Growth in liquid minimal medium [13] supplemented with succinic acid (at concentrations up to $300 \mathrm{mM}$ ) was measured in triplicate by optical density at $540 \mathrm{~nm}$. Colony growth over $48 \mathrm{~h}$ with alpha-terpeneol was carried out using agar plates with holes punched out or overlaying filter paper discs presoaked in alpha-terpeneol and then placed on a carpet of the test cells. Alpha-terpeneol was used at concentrations from full strength $(100 \%)$ to $0.4 \%$ (diluted in 20\% Tween 20). Cell metabolic activity during dormancy (where growth had been suspended in cultures of $1 \%$ Bacto-tryptone for $>30$ days) versus cells grown 
overnight in fresh $0.1 \%$ Bacto-tryptone medium was measured by the uptake of rhodamine 123, according to the method of Kaprelyants and Kell [13, 14], using a FACScan counter (Becton Dickenson, San Jose, CA) set at wavelengths of 480 to $540 \mathrm{~nm}$.

Two commercially available kits, EcoPlate (Biolog, Israel) and API (BioMerieux, France), were used to determine substrate utilization of each isolate according to the manufacturer's instructions. Fatty acid methyl ester (FAME) profiles were also carried out using gas liquid chromatography as described previously [10]. Oxygen uptake was measured using an Oxygen Monitor 53 (Yellow Springs Instrument, Yellow Springs, OH). Bacteria grown in the $1 \%$ Bacto-tryptone medium were washed three times in Czapek's salts to which supplements of $100 \mathrm{mM}$ of various substrates were added. A period of $\sim 5$ min preceded the oxygen measurements. Percentage change in the slope of oxygen consumption with a supplement was compared to the endogenous rate over a 5-min interval.

Genetic Characterization. DNA extracted from the bacteria was purified and used as a template for polymerase chain reaction (PCR) amplification of a fragment of the 16S rRNA gene (using identical primers and conditions described previously [10]). Sequenced PCR products were compared with all other known DNA sequences on GenBank through a BLAST search (http:// www.ncbi.nlm.nih.gov/blast). 16S rRNA sequences of the amber isolates were then aligned with other bacteria, and a phylogeny was constructed with MEGA2.1 (http:// www.megasoftware.net) using the neighbor-joining method with a Kimura two-parameter distance matrix taking into account transitional and transversional substitution rates. An estimated age for each isolate using $16 \mathrm{~S}$ rRNA sequence divergence to modern isolates was calculated, again using a Kimura two-parameter matrix on MEGA 2.1 [9]. PCR amplification of the gene encoding a putative "resuscitation-promoting factor" (Rpf) was as described by Mukamolova et al. [25] using standard conditions with AmpliTaq Gold (Applied Biosystems, Foster City, CA). Partial sequences of the Rpf gene (isolate 4) were submitted to GenBank under Bankit number 554367.

\section{Results and Discussion}

Isolation and Characterization of Bacteria Isolated from Amber. Out of 12 isolates grown from the amberflake TSB suspension, three, designated as isolates 4, 27, and 29, all showed characteristic cell organization (tetrad formations) (see Fig. 1) and coloration (bright yellow) consistent with that of Micrococcus luteus. Controls throughout the extraction process, such as growth within the primary medium containing the 1-g surface-sterilized amber block, and control TSB agar plates monitored at every stage of extraction remained negative, indicating the sterility of the procedure and clearly demonstrating that the bacteria came from within the amber block.

A 774-bp fragment of the $16 \mathrm{~S}$ rRNA gene was sequenced from the three isolates and compared with all other known sequences through a GenBank BLAST search and found to be most closely related to a M. luteus 16S rRNA sequence (AJ409096) differing by one, three, and one base pairs (bp), respectively. Alignment with other members of the Micrococcus genus (or related bacteria) in a neighbor-joining tree (Fig. 2) clearly places these amber isolates within a clade consistent with their identification as M. luteus. Under established standards of $16 \mathrm{~S}$ rRNA systematics, where isolates sharing $>97 \%$ identity should be considered as the same species [35], comparison between the amber isolates and published sequences clearly indicates that they should be considered as strains of $M$. luteus.

Biochemical characterization of substrate utilization for each isolate compared with those from a broad range of bacterial species indicated that two of the isolates (4 and 27) successfully use maltose, turanose, methyl pyruvate, and gamma-hydroxybutyric acid, while differing in their use of lactic acid (4) and inosine alpha-Dglucose, sucrose, and alpha-ketoglutaric acid (27). All three isolates were uniformly sensitive to all antibiotics, except for marginal resistance to oxycillin. FAME analysis and limited results using the commercially available API kits are compatible with the isolates being closely related to micrococci (Table 1), although the results with alternative kits were unable to identify the species.

Estimating the Age of the Amber Isolates. Using the method applied to the Permian bacteria by Graur and Pupko [9], the isolates described here differ from the reference M. luteus $16 \mathrm{~S}$ rRNA sequence (AJ409096) by a maximum of 0.0034 nucleotide substitutions per site (excluding ambiguous sites). Given a rate of substitution of between $1 \times 10^{-8}$ and $5 \times 10^{-8}$ substitutions per site per year (as given in [9]) this translates to an estimate of the time of divergence between our isolates and the reference isolate as between 34,000 and 170,000 years for the isolates. With the rigorous controls described above, the genetically determined age of the bacteria isolated from the amber therefore would appear to be at odds with the amber block's geological age.

This discrepancy between the age of the amber and the age inferred by genetic comparison mirrors the considerable debate about the age of bacteria isolated from other deposits of significant age. For example, genetic analysis of the recently isolated bacteria from 250million-year-old Permian salt crystals [37] is unable to confirm or disprove the ancient age of these isolates [9, $22,28]$. Here, one possible explanation for this seeming 


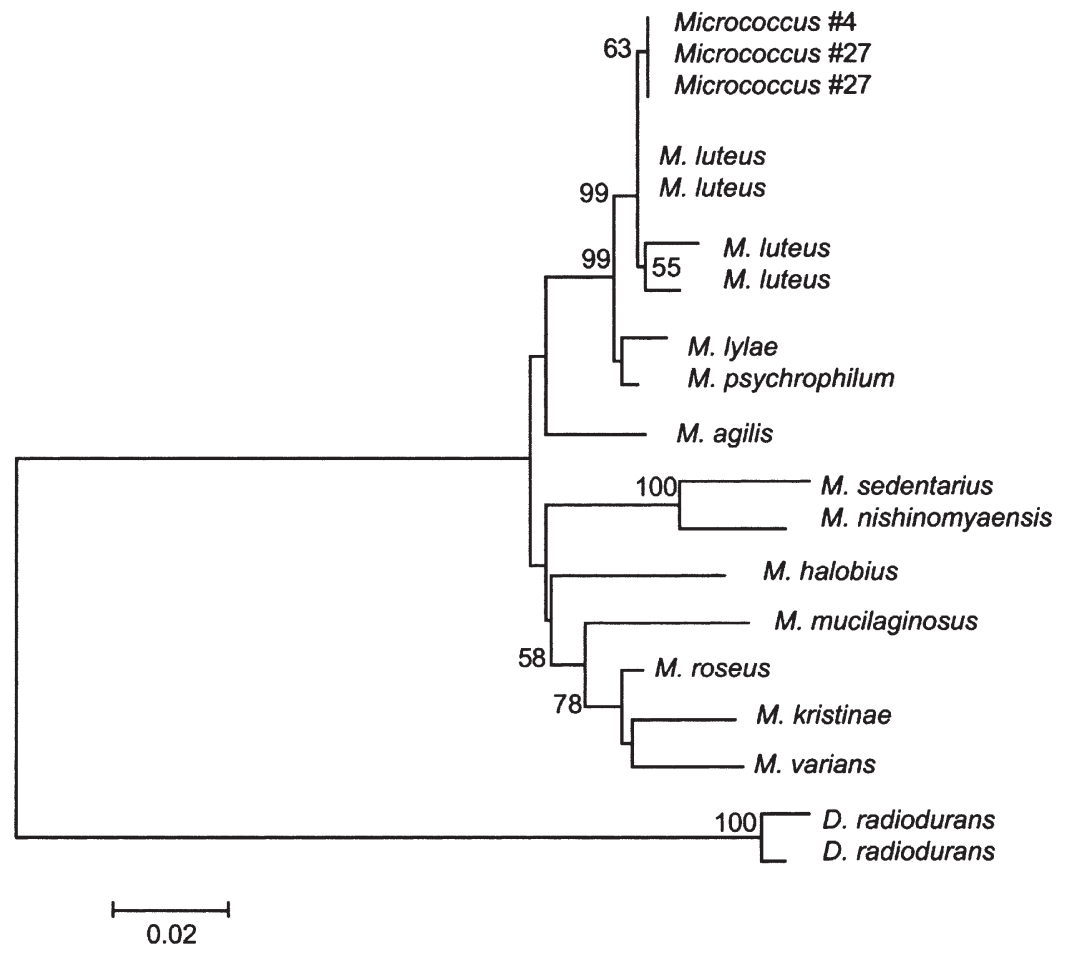

Figure 2. Neighbor-joining tree of aligned partial sequence of $16 \mathrm{~S}$ rRNA showing relationships between Micrococcus related species and the strains isolated from amber here (4, 27, and 29). Numbers are bootstrap values $(>50)$ for 1000 replicates. Accession numbers (excluding amber isolates) from top to bottom: AJ409096, AF501366, AF234843, AF234861, AF057290, AJ005932, X80748, X87755, X87757, X80747, X87758, X87756, X80749, X87754, AF289089, M21413. contradiction might be that the bacteria may have become entrapped at a later time in the amber block than its initial deposition through microscopic fissures in the rock (as noted in amber blocks used previously to isolate ancient bacteria [10]) or following exposure and reburial of geological formations. Analysis of other well-studied genes, as will be done in a later section, from these bacteria in comparison with modern Micrococcus isolates may help to resolve this. Additionally, given that there have been a number of cases of conflicts between geological age and the genetically inferred age of bacteria isolated from ancient deposits, a more detailed understanding of the rate of evolution of bacterial genes over considerable time may help to bring clarity to this field of discussion.

Prerequisites for Long-Term Survival. Irrespective of whether the amber isolates are tens of thousands or millions of years old, the repeated finding of Micrococcuslike species in amber suggests that these bacteria possess a number of mechanisms that favor survival in nutrientpoor environments over extended periods of time. We envisage three requirements that an entombed bacterium would need as prerequisites for long-term survival: (1) During the initial more fluid stages of resin formation suitable substrates must be available, and the organism should possess the capacity to utilize them. (2) As the resins polymerize and form a solid block the organism must be capable of entering dormancy, during which division may be arrested, but minimal physiological maintenance functions should be maintained, probably requiring a minimal energy source. (3) Finally, while they may remain viable but unculturable there must be a mechanism of reversing this state when conditions arise conducive to growth and proliferation.

1. Initial Survival and Substrate Utilization. The Latin name for amber is succinum, meaning "sap stone." Some $3-8 \%$ of its content consists of a four-carbon dicarboxylic acid-succinic acid [2, 16]. Detailed analysis of the growth of one of the isolates (4) in repeated experiments using a simple $0.1 \%$ Bacto-tryptone broth or the minimal succinic acid medium [7] showed a significantly increased rate of growth of $\sim 400 \%$ in the first $7 \mathrm{~h}$ when the

Table 1. Biochemical and genetic identification of bacterial isolates from amber

\begin{tabular}{|c|c|c|c|}
\hline Isolate & FAME (score) & $A P I$ & BLAST results (similarity in base pairs) \\
\hline 4 & M. luteus (0.529) & Micrococcus spp. & 16S rRNA M. luteus ${ }^{\mathrm{a}}(773 / 774)$ \\
\hline 27 & M. luteus (0.614) & No match & 16S rRNA $M$. luteus $^{\mathrm{a}}(771 / 774)$ \\
\hline 29 & M. luteus (0.545) & No match & 16S rRNA $M$. luteus $^{\mathrm{a}}(773 / 774)$ \\
\hline
\end{tabular}

${ }^{\mathrm{a} A c c e s s i o n}$ number AJ409096. 
A)

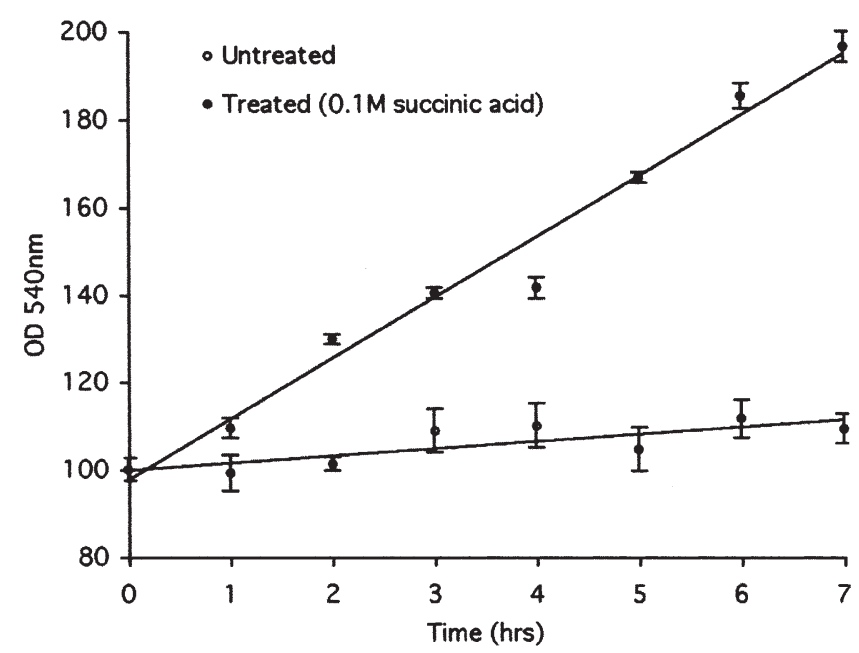

B)

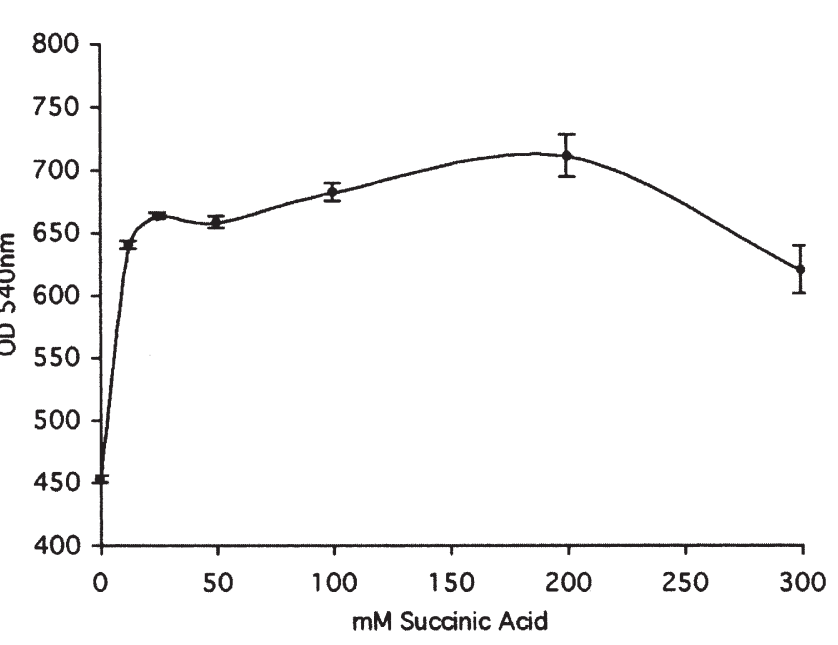

Figure 3. Growth of bacteria isolate 4 in a $0.1 \%$ Bacto-tryptone minimal medium. (A) Comparative growth of bacteria with or without the addition of succinic acid (up to $300 \mathrm{mM}$ ) measured by optical density (OD) at $540 \mathrm{~nm}$. (B) Comparison of growth of bacteria grown at varying levels of succinic acid for $7 \mathrm{~h}$, collected, and read by OD at $540 \mathrm{~nm}$. Bars indicate standard deviation of triplicate readings.

medium was supplemented with succinic acid (100 mM final concentration) (Fig. 3A). There is an apparent plateau in the growth of the supplemented and unsupplemented cultures at $4 \mathrm{~h}$. Comparison of growth at a number of different concentrations reveals that even $12.5 \mathrm{mM}$ succinic acid is sufficient to stimulate growth. Concentrations $>200 \mathrm{mM}$ are apparently inhibitory, with growth decreasing (Fig. 3B); $200 \mathrm{mM}$ is the equivalent of $2.4 \%$ succinic acid. In addition to growth, morphological investigation under phase contrast microscopy indicated that bacteria growing in the $0.1 \%$ Bacto-tryptone broth appeared in disorganized clumps, while those in broth supplemented with succinic acid showed a highly ordered tetrad structure (Fig. 1C). Using Czapek-agar minimal medium plates, this translated into large domed colonies in the succinic acid supplemented plates with control plates showing much smaller colonies (Fig. 4). Uptake of oxygen in the amber isolates also responded to the addition of $100 \mathrm{mM}$ succinic acid (an increase of 40\%) compared to the basal salt solution. This was lower than that produced by an equimolar concentration of pyruvic acid $(+95 \%)$, but more than that with lactic $(+11 \%)$ or malic acid $(+31 \%)$. It is interesting to note, in relation to the ability of these bacteria to utilize succinic acid, that early characterization of succinic acid dehydrogenase used the enzyme from a Micrococcus species [5, 38], as well as more recent characterization of the catalytic functions of the same enzyme in its membrane-associated form [18]. Together this suggests that M. luteus has the means to utilize succinic acid and demonstrates evidence that its growth is stimulated by the presence of succinic acid at concentrations within the lower range of that found in amber. In nature, succinic acid may therefore provide a potentially invaluable resource to maintain growth of the bacteria in the initial stages of amber formation.

There are indications that Micrococcus luteus may be able to exploit other substrates present in amber. For example, $M$. luteus was an early source for the cloning of the cis-prenyl transferase gene [30, 34], whose gene product carries out the condensation of isopentenyl phosphate with allylic diphosphate. This is an essential

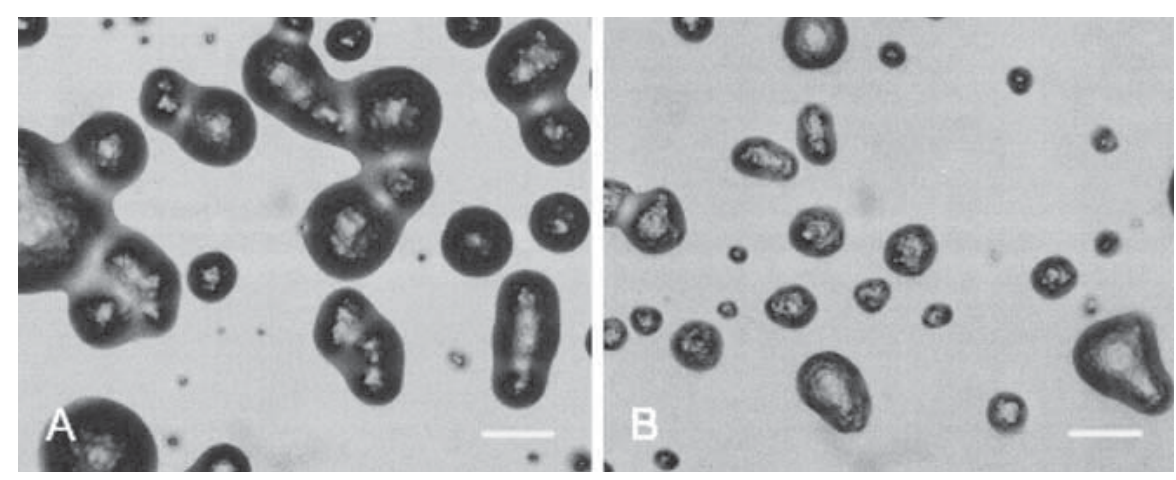

Figure 4. Comparative morphology of bacterial colonies of Micrococcus isolate 4 grown (A) with and (B) without succinic acid on Czapek-agar plates. Scale bar indicates $50 \mu \mathrm{m}$. 

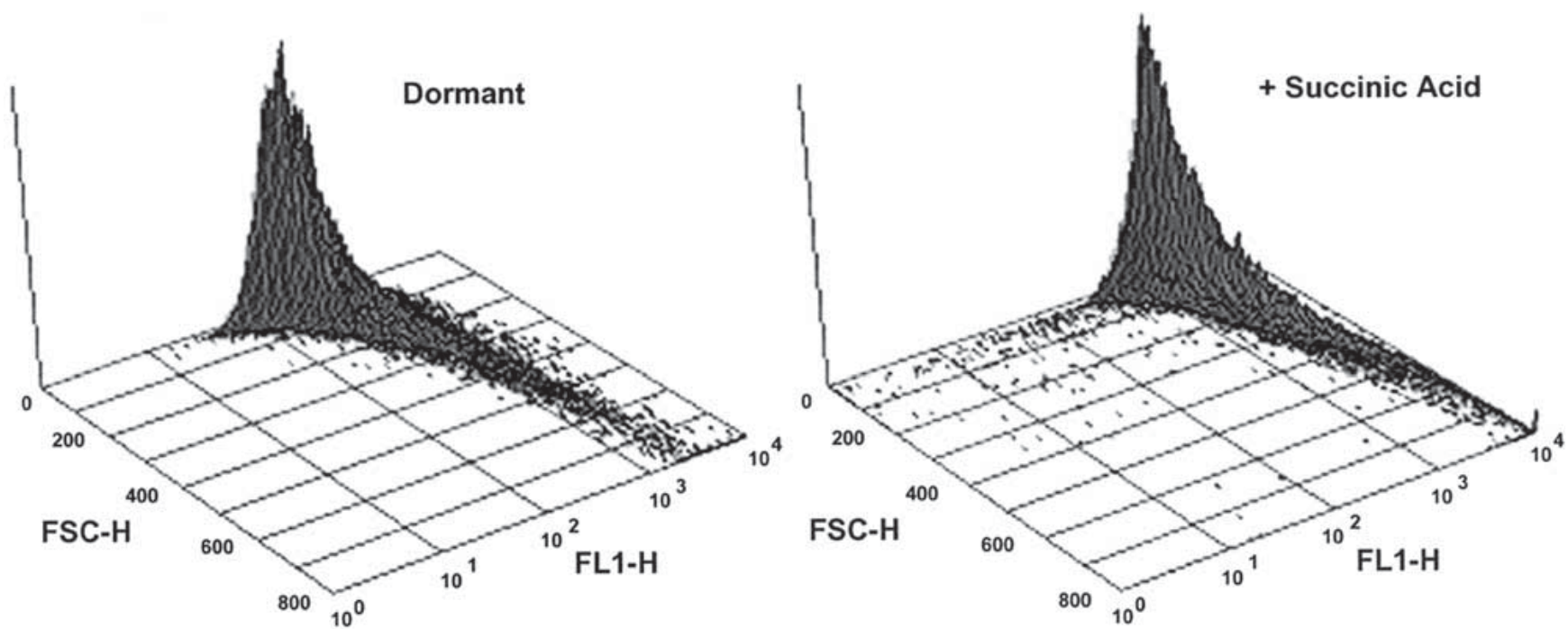

FSC-H (foward scatter - cell size)

FL1-H (fluoresence intensity - dye concentration)

Figure 5. Distribution of fluorescence (as measured by excitation and emission wavelengths of $480 \mathrm{~nm}$ and $520 \mathrm{~nm}$, respectively) of isolate 4 following staining with $0.3 \mu \mathrm{M}$ rhodamine 123. (A) Cells grown in 1\% Bacto-tryptone medium and left for 30 days prior to staining. (B) Dormant cell culture was placed into fresh $0.1 \%$ Bacto-tryptone minimal medium and grown overnight at $30^{\circ} \mathrm{C}$.

step in the biosynthesis of terpenes, which are another major component of amber. Additionally, the membranes of $M$. luteus are rich in enzymes that utilyze prenyl pyrophosphates as donors in prenylation reactions [32], an observation that supported the view of the centrality of menaquinone biosynthesis. Although succinic acid is not on the direct mevalonic acid pathway to terpenes, it is probably metabolically linked through the activities of menaquinone, an isoprene product, as a cofactor in its oxidation. Mechanisms to withstand exposure to alphaterpeneol (another constituent of amber) are also present in M. luteus. In our own growth studies three Staphylococcus-related species (isolated from amber, an archaeological bone specimen, and a modern skin isolate, respectively), all showed large no-growth zones around the placement of alpha-terpeneol either on a filter or in a well within the agar plate (see Materials and Methods). Isolate 4, however, continued to grow right up to contact with alpha-terpeneol and, although growth was more restricted, clearly indicated a resistance toward this chemical. A detailed scientific report of Tea Tree oil (rich in terpines) gives minimum bactericidal concentrations $(\mathrm{MBC})$ and minimal inhibitory concentrations (MIC) values for $M$. luteus of $0.25-6.0 \%$ and $0.06-0.5 \%$, respectively [4]. Although it is difficult to directly compare these values to our results, it seems that our isolates are more resistant to growth inhibition than the extant strains used in these studies.

2. Dormancy. There is strong evidence that Micrococcus luteus is capable of entering long-term dormancy $[25,26]$. The effects of long-term starvation on these bacteria in culture are clearly seen when comparing the extent of fluorescence in dormant (left in spent medium for $>30$ days) vs growing cultures. Fluorescent cell sorting based on the uptake of rhodamine 123 (which is selectively taken up by metabolically active cells $[13,14]$ ) clearly shows a shift of 10-fold difference in fluorescence between cells that have been dormant for over a month in $1 \%$ Bacto-tryptone medium versus those grown overnight in fresh minimal medium (Fig. 5). This clearly shows that $M$. luteus can down-regulate its metabolism and is able to reactivate it on placement in new media [14].

Morita [24] has suggested that, during cell dormancy, two functions are required to maintain cellular integrity: DNA repair and the prevention of racemization. For these to be carried out under low levels of oxygen (remembering that $M$. luteus is an obligate aerobe) molecular hydrogen may be the source of energy [24]. A possible alternative solution would be the presence of trapped oxygen in amber, the subject of a number of investigations [11]. There is no agreement on whether this is truly ancient air, but amber does contain gas bubbles containing a significant oxygen concentration. Further studies are needed to measure the minimal oxygen requirements of Micrococcus, to test Morita's hypothesis, and to determine the possible role molecular hydrogen may play in long-term bacterial survival.

3. Reanimation. Finally, and perhaps in anticipation of their ability to "slumber," M. luteus produces a "revival" factor capable of breaking the viable but unculturable status of bacteria that are seemingly dormant [25, $26]$. The gene for this revival factor, $R p f$, is found widely 


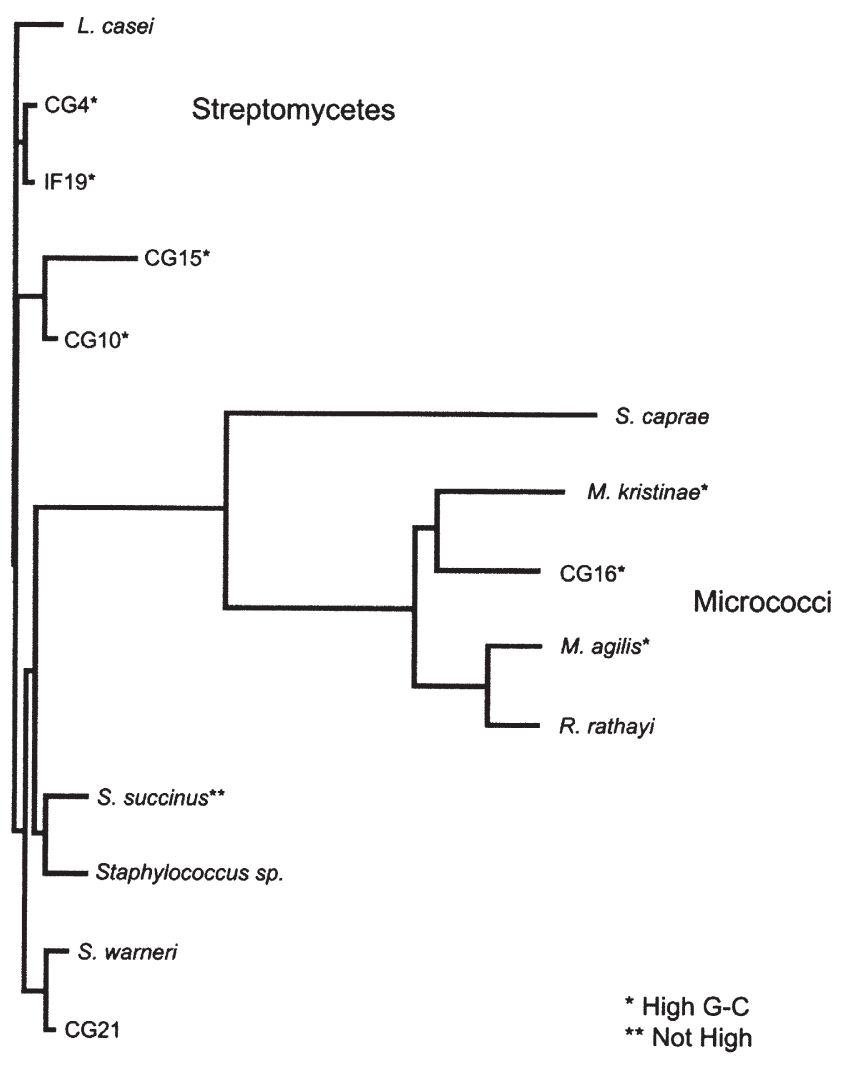

Figure 6. Phylogenetic tree of bacteria isolated from amber. The asterisk indicates those which are $\mathrm{G}+\mathrm{C}$ rich. Staphylococcus succinus is not a high $\mathrm{G}+\mathrm{C}$ organism, but two of its fatty acids, tuberculostearic acid and meso-diaminopimelic acid, are typical of high $\mathrm{G}+\mathrm{C}$ coryneform bacteria.

among the Gram-positive, high $\mathrm{G}+\mathrm{C}$ bacteria, members of which we have found in amber [10] (Fig. 6). This characteristic of their DNA not only may relate to $R p f$ but also may confer some stability to high pressure or temperature given the higher melting temperature of their DNA. Staphylococcus succinus, which although not a high $\mathrm{G}+\mathrm{C}$ organism has also been isolated from amber [17], has two fatty acids (tuberculostearic acid and meso-diaminopimelic acid acid) that are typical of high $\mathrm{G}+\mathrm{C}$ coryneform bacteria.

We have successfully amplified the Rpf gene from all three of the amber isolates. On comparison to the Rpf gene in the published Fleming strain of M. luteus (accession no. Z96935), there is a major insertion. Two of the amber isolates (27 and 29) have the same size insertion (234 bp) while one (4) has a smaller one (199 bp). Sequencing reveals that the insertion lies in a hinge region of the molecule which links the LysM motif to the functional portion of the gene (M. Young, personal communication, Aberystwyth, Wales, 2003). This motif is found in a number of enzymes described as "involved in bacterial cell wall degradation" (NCBI
Blast search). This highlights that although the $16 \mathrm{~S}$ rDNA may be similar between the extant strains and amber isolates, other genes may show considerable differences.

\section{Conclusions}

The genus Micrococcus seems to be surprisingly well suited for long-term survival in extreme environments, a factor that may well explain its repeated isolation from fossilized amber. Other closely related cocci, which like $M$. luteus are non-spore-forming, also appear well suited to extreme environments. Deinococcus radiodurans (previously called Micrococcus radiodurans) is able to withstand 50-100 times more ionizing radiation than Escherichia coli [23] as well as other DNA-damaging conditions (e.g., UV light, hydrogen peroxide) and desiccation [21]. Another close relative, Micrococcus roseus, has such high carotenoid content that it is believed to be suited for life in the upper stratosphere at very low atmospheric pressures [1,20], as its Micrococcus albus [12]. Interestingly, $M$. roseus has also been shown to be able to withstand growth in high-atmospheric-pressure environments [36]. In addition to survival in extreme environments the group also appears able to use unusual metabolic sources for nutrition: for example, soil isolates of the genus are capable of using diphenyl as a sole carbon source [33], which may give them an important role in bioremediation.

In summary, we have isolated bacteria from 120million-year-old amber, which by genetic, morphologi$\mathrm{cal}$, and biochemical analysis are identified as belonging to the species Micrococcus luteus. Using diverse molecular and cell biological techniques, we have produced evidence supporting the view that these (and related modern members of the species) have numerous adaptations for survival in extreme, nutrient poor environments. These traits assist in the bacteria's persistence and dispersal in the environment. The precise age of the bacteria cannot be confirmed. Future total genomic sequencing of environmental bacteria showing long-term survival is likely to shed light on the validity of the 16S rDNA as a universal chronometer. The ability of M. luteus to endure in the hostile environment provided by a block of amber highlights this microbe as a superbly adapted bacterial survivor.

\section{Acknowledgments}

We are grateful to the Center for the Study of Emerging Diseases for their generous support. Professor A. Nissenbaum from the Weizmann Institute of Science kindly provided the samples of amber used in the study. 


\section{References}

1. Bamji, MS, Krinsky, NI (1966) The carotenoid pigments of a radiation-resistant Micrococcus species. Biochim Biophys Acta 115: 276-284

2. Budavari, S (1989) The Merck Index. Merck \& Co, Rahway, NJ

3. Cano, RJ, Borucki, MK (1995) Revival and identification of bacterial spores in 25- to 40-million-year-old Dominican amber. Science 268: 1060-1064

4. Carson, CF, Riley, TV (1998) Antimicrobial activity of tea tree oil - a report for the Rural Industries Research and Development Corporation (Australia). RIRDC Publication number 98/70, pp 152 (http://wwwrirdcgovau/reports/TTO/UWA-24Adoc)

5. Crowe, BA, Owen, P (1983) Molecular properties of succinate dehydrogenase isolated from Micrococcus luteus (lysodeikticus). J Bacteriol 153: 1493-1501

6. Czapek, F (1922) Biochemie der Pflanzen, 3rd ed. Fischer, Jena

7. Davey, HM, Kaprelyants, AS, Kell, DB (1993) Flow cytometric analysis, using rhodamine 123, of Micrococcus luteus at low growth rate in chemostat culture. In: Lloyd, D (Ed.) Flow Cytometry in Microbiology, Springer-Verlag, London, pp 83-93

8. Galippe, V (1920) Recherches sur la resistence de microzymes a l' action du temps et sur leur survivance dans l'amber. Compt Rend Acad Sci (Paris) 170: 856-858

9. Graur, D, Pupko, T (2001) The Permian bacterium that isn't. Mol Biol Evol 18: 1143-1146

10. Greenblatt, CL, Davis, A, Clement, BG, Kitts, CL, Cox, T, Cano, RJ (1999) Diversity of microorganisms isolated from amber. Microb Ecol 38: 58-68

11. Hopfenberg, HB, Witchey, LC, Poinar, GO, Beck, CW, Chave, KE, Smith, SV, Horibe, Y (1988) Is the air in amber ancient? discussions and reply. Science 241: 717-724

12. Imshenetsky, AA, Lysenko, SV, Lach, SP (1979) Microorganisms of the upper layer of the atmosphere and the protective role of their cell pigments. Life Sci Space Res 17: 105-110

13. Kaprelyants, AS, Kell, DB (1992) Rapid assessment of bacterial viability and vitality using rhodamine 123 and flow cytometry. J Appl Bacteriol 72: 410-422

14. Kaprelyants, AS, Kell, DB (1993) Dormancy in stationary-phase cultures of Micrococcus luteus: flow cytometric analysis of starvation and resuscitation. Appl Environ Microbiol 59: 3187-3196

15. Kennedy, MJ, Reader, SL, Swierczynski, LM (1994) Preservation records of microorganisms: evidence of the tenacity of life. Microbiology 140: 2513-2529

16. Lambert, JB, Frye, JS (1982) Carbon functionalities in amber. Science 217: 55-57

17. Lambert, LH, Cox, T, Mitchell, K, Rossello-Mora, RA, Del Cueto, C, Dodge, DE, Orkand, P, Cano, RJ (1998) Staphylococcus succinus sp nov, isolated from Dominican amber. Int J Syst Bacteriol 48: 511-518

18. Lancaster, CR (2002) Succinate:quinone oxidoreductases: an overview. Biochim Biophys Acta 1553: 1-6

19. Madigan, MT, Martinko, JM, Parker, J (2000) Brock: Biology of Microorganisms, 9th ed. Prentice Hall, Upper Saddle River, NJ

20. Mathews, MM, Krinsky, NI (1965) The relationship between carotenoid pigments and resistance to radiation in non-photosynthetic bacteria. Photochem Photobiol 4: 813-817
21. Mattimore, V, Battista, JR (1996) Radioresistance of Deinococcus radiodurans: functions necessary to survive ionizing radiation are also necessary to survive prolonged desiccation. J Bacteriol 178: 633-637

22. Maughan, H, Birky Jr, CW, Nicholson, WL, Rosenzweig, WD, Vreeland, RH (2002) The paradox of the "ancient" bacterium which contains "modern" protein-coding genes. Mol Biol Evol 19: 1637-1639

23. Minton, KW, Daly, MJ (1995) A model for repair of radiationinduced DNA double-strand breaks in the extreme radiophile Deinococcus radiodurans. Bioessays 17: 457-464

24. Morita, RY (1999) Is $\mathrm{H}_{2}$ the universal energy source for long-term survival? Microb Ecol 38: 307-320

25. Mukamolova, GV, Kaprelyants, AS, Young, DI, Young, M, Kell, DB (1998) A bacterial cytokine. Proc Natl Acad Sci USA 95: 89168921

26. Mukamolova, GV, Kormer, SS, Kell, DB, Kaprelyants, AS (1999) Stimulation of the multiplication of Micrococcus luteus by an autocrine growth factor. Arch Microbiol 172: 9-14

27. Nicholson, WL, Munakata, N, Horneck, G, Melosh, HJ, Setlow, P (2000) Resistance of Bacillus endospores to extreme terrestrial and extraterrestrial environments. Microbiol Mol Biol Rev 64: 548-572

28. Nickle, DC, Learn, GH, Rain, MW, Mullins, JI, Mittler, JE (2002) Curiously modern DNA for a " 250 million-year-old" bacterium. J Mol Evol 54: 134-137

29. Nissenbaum, A (1975) Lower Cretaceous amber from Israel. Naturwissenschaften 62: 341-342

30. Oh, SK, Han, KH, Ryu, SB, Kang, H (2000) Molecular cloning, expression, and functional analysis of a cis-prenyltransferase from Arabidopsis thaliana. Implications in rubber biosynthesis. J Biol Chem 275: 18482-18488

31. Poinar, GO, Poinar, R (1994) The Quest for Life in Amber. Addison-Wesley, New York

32. Saito, Y, Ogura, K (1981) Biosynthesis of menaquinones Enzymatic prenylation of 1,4-dihydroxy-2-naphthoate by Micrococcus luteus membrane fractions. J Biochem (Tokyo) 89: 1445-1452

33. Salton, MR, Schmitt, MD (1967) Effects of diphenylamine on carotenoids and menaquinones in bacterial membranes. Biochim Biophys Acta 135: 196-207

34. Shimizu, N, Koyama, T, Ogura, K (1998) Molecular cloning, expression, and purification of undecaprenyl diphosphate synthase No sequence similarity between E- and Z-prenyl diphosphate synthases. J Biol Chem 273: 19476-19481

35. Stackebrandt, E, Goebel, BM (1994) Taxonomic note: a place for DNA-DNA reassociation and $16 \mathrm{~S}$ rRNA sequence analysis in the present species definition in bacteriology. Int J Syst Bacteriol 44: 846-849

36. Tanaka, T, Burgess, JG, Wright, PC (2001) High-pressure adaptation by salt stress in a moderately halophilic bacterium obtained from open seawater. Appl Microbiol Biotechnol 57: 200-204

37. Vreeland, RH, Rosenzweig, WD, Powers, DW (2000) Isolation of a 250 million-year-old halotolerant bacterium from a primary salt crystal. Nature 407: 897-900

38. Warringa, MG, Giuditta, A (1958) Studies on succinic dehydrogenase. IX. Characterisation of the enzyme from Micrococcus lactilyticus. J Biol Chem 230: 111-123 